\title{
Prevalence of Thyroid Cancer in Hyperthyroid Patients Treated by Surgery
}

\author{
Everardo Zanella, M.D., ${ }^{1}$ Francesco Rulli, M.D., ${ }^{1}$ Marco Muzi, M.D., ${ }^{1}$ Mario Sianesi, M.D., ${ }^{2}$ \\ Daniele Danese, M.D., ${ }^{3,4}$ Salvatore Sciacchitano, M.D., ${ }^{3}$ Alfredo Pontecorvi, M.D. ${ }^{5,6}$ \\ ${ }^{1}$ Department of Surgery, University of Rome "Tor Vergata," Complesso Integrato Columbus, Via della Pineta Sacchetti 506, 00168 Rome, Italy \\ ${ }^{2}$ Department of Surgery, University of Parma, Ospedali Riuniti di Parma, Via Gramsci 2, 43100 Parma, Italy \\ ${ }^{3}$ Department of Experimental Medicine and Pathology, University of Rome "La Sapienza," Viale Regina Elena 324, 00161 Rome, Italy \\ ${ }^{4}$ Endocrinology Section, Institute of Forensic Medicine of Italian Air Force, Viale P. Gobetti 2, 00185 Rome, Italy \\ ${ }^{5}$ Molecular Oncogenesis Laboratory, "Regina Elena" Cancer Institute, Via delle Messi d'Oro 156, 00166 Rome, Italy \\ ${ }^{6}$ Institute of Internal Medicine, Catholic University, Largo F. Vito 1, 00168 Rome, Italy
}

\begin{abstract}
A retrospective study has been carried out to evaluate the prevalence of malignant thyroid tumors in 202 patients submitted to surgery for hyperthyroidism. Thyroid cancer was diagnosed in 12 cases (5.9\%); the final histologic examination revealed nine papillary carcinomas, one follicular carcinoma, and two Hürthle cell carcinomas. Concurrence of hyperthyroidism and thyroid cancer was more frequent in patients with single toxic adenomas than in those with toxic diffuse or multinodular goiters. In five cases thyroid malignancy was detected in the context of the hyperthyroid lesion (three toxic adenomas and two diffuse goiters). In eight patients the malignant lesion showed a maximum diameter of less than $1 \mathrm{~cm}$, although in five of these cases unfavorable histologic features, such as minimal capsular invasion or multifocality, were present. All patients presenting with thyroid cancer are currently alive and apparently free of residual disease. It is concluded that hyperthyroid patients, particularly those with single toxic adenomas, should be carefully evaluated to exclude the presence of an associated malignancy and to plan the most appropriate therapeutic options.
\end{abstract}

Several studies have been carried out to evaluate the clinical relevance of the association between malignancy and hyperfunction of the thyroid gland. Although the results of these studies show a certain amount of variability and some discrepancies, they generally indicate that the coexistence of hyperthyroidism and thyroid cancer should no longer be considered a rare finding [1-5]. Indeed, in more recent series the prevalence of malignancy in hyperthyroid patients tends to be even higher, probably the consequence of more detailed investigations. In most of these studies thyroid cancer appears to be associated more frequently with toxic nodular goiter than with diffuse goiter (Graves' disease) [6-8].

The aim of the present study was to assess the clinical relevance of the association between thyroid cancer and hyperthyroidism by retrospective analysis of 202 hyperthyroid patients previously submitted to surgery. The results confirm that the prevalence of thyroid cancer in the context of a hyperfunctioning thyroid gland is greater than expected $(5.9 \%)$ and suggest that all hyperthyroid

Correspondence to: D. Danese, M.D., 77 Via E. Q. Visconti, 00193 Rome, Italy. patients be carefully examined to rule out the possibility of this association.

\section{Patients and Methods}

Records from 202 hyperthyroid patients, 54 men (26.8\%) and 148 women $(73.2 \%)$ aged 22 to 88 years (mean 53.5 years), who had been submitted to surgery for treatment of the hyperthyroid condition during the last 20 years were retrospectively evaluated. None had a history of external irradiation during childhood.

Criteria used for selecting patients for surgery included the presence of a large goiter with evidence of tracheal or esophageal compression (or both), clinical suspicion of malignancy, failure or side effects of medical treatment (or both), or the patient's request. Methimazole treatment and administration of Lugol's solution for 5 days were typically used prior to surgery to achieve the euthyroid state.

Two surgical teams, under the supervision of the same surgeon (E.Z.), carried out the thyroid surgery. It predominantly consisted in subtotal or total thyroidectomy for the treatment of toxic, diffuse, and multinodular goiters and prominent, toxic adenomas associated with nonfunctioning nodular lesions detectable clinically or sonographically. Toxic adenomas that presented as solitary thyroid nodules were mostly treated by lobectomy with associated isthmusectomy. Patients with thyroid carcinoma that had previously been submitted to partial thyroidectomy underwent a second surgery to achieve total thyroidectomy.

Thyroid neoplasms were classified according to World Health Organization (WHO) criteria. Histologic specimens were reexamined by two independent pathologists according to the standard criteria described by Rosai [9] and graded according to the TNM age-related classification of thyroid malignancies [10]. In the presence of malignant lesions $>1 \mathrm{~cm}$ or exhibiting multifocality, ${ }^{131} \mathrm{I}$ ablative therapy $(80-150 \mathrm{mCi})$ was performed to remove thyroid remnants.

Follow-up of patients with thyroid cancer was performed by assessing serum thyroglobulin levels every 6 months. ${ }^{131} \mathrm{I}$ whole 
Table 1. Hyperthyroidism and thyroid malignancy.

\begin{tabular}{|c|c|c|c|c|c|c|c|c|}
\hline \multirow[b]{2}{*}{ Patient } & \multirow[b]{2}{*}{ Sex } & \multirow{2}{*}{$\begin{array}{l}\text { Age } \\
\text { (years) }\end{array}$} & \multirow[b]{2}{*}{ Diagnosis } & \multicolumn{3}{|c|}{ Tumor histology } & \multirow[b]{2}{*}{ TNM stage } & \multirow[b]{2}{*}{ Clinical stage } \\
\hline & & & & Type & Size $^{a}$ & Findings & & \\
\hline Z.C. & $\mathrm{F}$ & 35 & TA & Papillary & 0.5 & $\begin{array}{l}\text { Minimal capsular invasion } \\
\text { and bifocality }\end{array}$ & T4N0M0 & I \\
\hline E.E. & $\mathrm{F}$ & 69 & TA & Papillary & 1.0 & & T1N0M0 & I \\
\hline R.C. & $\mathrm{F}$ & 70 & TA & Papillary & 0.5 & & T1N0M0 & II \\
\hline I.V. & M & 35 & TA & Hürthle cell & 0.5 & Bifocality & T1N0M0 & I \\
\hline C.N. & $\mathrm{F}$ & 68 & TA & Hürthle cell & 2.0 & & T1N0M0 & I \\
\hline D.R. & $\mathrm{F}$ & 64 & TA & Papillary & 0.5 & & T1N0M0 & I \\
\hline C.Q. & $\mathrm{F}$ & 57 & TMNG & Papillary & 0.8 & $\begin{array}{l}\text { Minimal capsular invasion } \\
\text { and multifocality }\end{array}$ & T2N0M0 & II \\
\hline M.L. & $\mathrm{F}$ & 59 & TMNG & Papillary & 3.0 & & T4N0M0 & III \\
\hline M.S. & $\mathrm{F}$ & 40 & TDG & Papillary & 0.6 & Multifocality & T2N0M0 & II \\
\hline M.P. & $\mathrm{F}$ & 45 & TDG & Follicular & 3.0 & & T2N0M0 & II \\
\hline
\end{tabular}

TA: toxic adenoma; TMNG: toxic multinodular goiter; TDG: toxic diffuse goiter.

${ }^{a}$ Maximum diameter of thyroid carcinoma (centimeters); in the case of a multifocal lesion it refers to the maximum diameter of the largest tumoral focus.

Table 2. Relation between toxic adenoma and thyroid carcinoma.

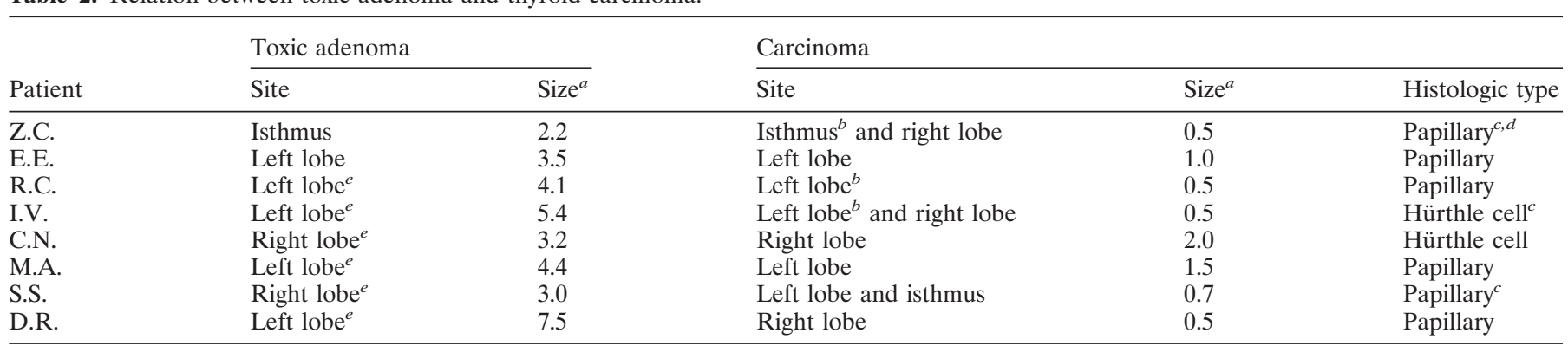

${ }^{a}$ Maximum diameter of thyroid lesion (centimeters).

${ }^{b}$ Inside toxic adenoma.

${ }^{c}$ Multifocal carcinoma.

${ }^{d}$ Minimal capsular invasion.

${ }^{e}$ Toxic adenoma was the only hyperfunctioning nodule in the context of a multinodular goiter.

body scanning after induction of transient hypothyroidism [thyroid-stimulating hormone $(\mathrm{THS})>30 \mathrm{U} / \mathrm{ml}$ ] was performed within 60 days and 3, 5, and 10 years after surgery.

\section{Results}

Among the 202 hyperthyroid patients investigated, 41 showed the presence of a single toxic adenoma, 123 had toxic multinodular goiter, and 38 presented with Graves' disease. Twelve patients (5.9\%), 11 women and one man (mean age 54.8 years; range 35-70 years) were later discovered to harbor a thyroid malignant lesion classified as papillary carcinoma in nine cases, follicular carcinoma in one case, and Hürthle cell carcinoma in two cases (Table 1). Thyroid surgery was complicated by the occurrence of acute hypoparathyroidism in two cases, but no permanent lesions of the laryngeal nerve were observed. The mean follow-up of patients with thyroid cancer was 76 months (range 6-228 months). All patients are currently alive and apparently free of residual disease.

\section{Thyroid Cancer and Toxic Adenoma}

Thyroid cancer was found in 8 of 41 patients with toxic adenomas (19.5\%: seven women, one man). In six cases the lesion presented a maximum diameter of $\leq 1 \mathrm{~cm}$ (occult carcinoma), although in three of them more than one tumoral focus was present (Table 2). Histologic signs of extracapsular invasion were evident in one bifocal papillary carcinoma, localized within the hyperfunctioning nodule (patient Z.C.). A second subcentrimetric tumoral focus was detected in the functionally suppressed contralateral lobe after complete removal of all remaining thyroid tissue. In patient E.E. a papillary carcinoma was localized in the same lobe, adjacent to the toxic adenoma (Table 2).

In six patients multiple nodules were associated with the toxic adenoma. In patient R.C. an occult papillary carcinoma was detected inside the hyperfunctioning nodule, and in patient I.V. a malignant bifocal Hürthle cell lesion also arose within the toxic adenoma as well as in the context of a nonfunctioning nodule localized in the contralateral lobe. In two patients (C.N. and M.A.), the malignant lesion was present in the same lobe as a distinct solid nonfunctioning nodule and as a toxic adenoma, 
respectively. In the remaining two cases (patients S.S. and D.R.), two occult papillary carcinomas were detected in the contralateral lobe because of the presence of multinodularity (Table 2).

\section{Thyroid Cancer and Toxic Multinodular Goiter}

Only two women $(1.6 \%)$ of the 123 patients with toxic multinodular goiter had a coexisting thyroid cancer. In one (C.Q.), the papillary carcinoma was multifocal (maximum diameter $0.5-0.8$ $\mathrm{cm})$. However the presence of minimal capsular invasion and considering the older age of the patient, classified this tumor as the most advanced in the entire patient series (Table 1). In the other patient (M.L.), a papillary carcinoma with a maximum diameter of $3 \mathrm{~cm}$ was detected, but no data were available regarding its relation with the hyperfunctioning nodules.

\section{Thyroid Cancer and Toxic Diffuse Goiter (Graves' Disease)}

Thyroid cancer was found in $2(5.3 \%)$ of 38 patients submitted to surgery for toxic diffuse goiter. Patient M.S., who presented with bilateral ophthalmopathy and an extremely high antiperoxidase antibody titer $(1: 25,000)$ was submitted to surgery owing to the dramatic increase in the volume (more than fourfold) of the thyroid gland. Histologic examination revealed the presence of three foci of papillary carcinoma, two localized in the right lobe with maximum diameters of 0.6 and $0.4 \mathrm{~cm}$, respectively, and one in the left lobe, measuring $0.6 \mathrm{~cm}$. The other patient (M.P.) underwent total thyroidectomy only after detection of a solid cold nodule with a maximum diameter of about $3 \mathrm{~cm}$ that, at final histology, was diagnosed as a thyroid follicular carcinoma.

\section{Discussion}

The incidence of thyroid cancer in hyperthyroid patients is highly variable, ranging between $0.4 \%$ and $21.5 \%$ [2, 11, 12]. This high variability is likely due to genetic and environmental factors, such as the amount of iodine intake, the different criteria adopted for surgical selection of patients, the extent of thyroidectomy, and the accuracy of the histologic analysis of removed thyroid tissue [13, 14]. In particular, performance of total thyroidectomy as the treatment of choice in hyperthyroid patients, is likely to increase the possibility of finding the so-called occult carcinomas [12], which have been reported to occur in the general population with a prevalence ranging between $0.45 \%$ and $35.6 \%[15,16]$. In our series of hyperthyroid patients, a malignant lesion $<1 \mathrm{~cm}$ in diameter was detected in eight cases, a prevalence (3.96\%) similar to that observed by Pingitore [7] in autopsy studies in a nonendemic region of Italy but lower than that $(10.6 \%)$ reported by Autelitano et al. [15] in patients originating from various Italian regions, including areas of endemic goiter. It is important to point out that in our series half of the occult carcinomas were detected in patients submitted to total thyroidectomy.

The increased popularity of total thyroidectomy for treating hyperthyroid and euthyroid multinodular lesions is expected to result in the detection of a greater number of occult carcinomas, which are generally considered, although not always [17], to be associated with a good prognosis $[18,19]$. In addition to total thyroidectomy, another source of occult thyroid lesions is represented by sonography-guided fine-needle aspiration (FNA) biopsy, which is increasingly utilized for the preoperative investiga- tion of thyroid nodules, particularly those of smaller, pericentrimetric size [20]. These facts are already creating serious clinical dilemmas regarding the most appropriate diagnostic and therapeutic management of patients harboring occult carcinomas, as a consensus on how to handle this type of lesion has not been clearly established [21].

The association between thyroid carcinoma and toxic adenoma has been considered rare, only 50 cases being reported in the literature up to 1974 [3]. More recent studies have reported a highly variable incidence of thyroid carcinoma, ranging between $0.3 \%$ and $15.0 \%[2,22]$. In the present series of 41 hyperthyroid patients with toxic adenoma, a malignant lesion was detected in 8 cases $(19.5 \%)$. In about two-thirds of the patients thyroid cancer was present outside the toxic adenoma, in the functionally suppressed thyroid tissue (Table 2). These results are in agreement with those of Hamburger [22]. However, in three cases the malignant lesion was homolateral to the toxic adenoma, and in two cases it was detected after histologic examination of the surgically removed contralateral lobe. In rare instances thyroid carcinoma was embedded in or adjacent to the hyperfunctioning thyroid adenoma [23-26], appearing as a cold area within the autonomous lesion itself [27]. This observation is clinically relevant, as it indicates that not all "cold" areas inside a "hot" nodule should be considered the result of tissue necrosis or hemorrhage. In the three patients presenting with a thyroid carcinoma in the context of a "hot" nodule, the thyroid scan failed to detect cold areas, as the maximum internal diameter of the malignant lesion was below the detection limit of the technique. An analysis of the oncogenic profile of the two cell populations (i.e., occurrence of mutations of TSH receptor and the gsp and ras proto-oncogenes), ideally performed on FNA cytologic materials, may lead to better understanding of the molecular pathogenesis of thyroid cancer arising within a differentiated thyroid lesion. Occasionally, the entire thyroid toxic nodule is malignant [28-30], as we recently observed in a single case of hyperthyroid thyroid carcinoma [31] not included in this series. The occurrence of thyroid carcinoma masquerading as an autonomously functioning thyroid lesion, however, is rare and requires careful evaluation because many such cases fail to be included in this category after accurate reexamination of the clinical and pathologic records [32].

In agreement with several findings reported by other authors [6] in patients with toxic multinodular goiter, a $1.6 \%$ rate of associated malignancy was observed. The reason for the lower incidence of thyroid cancer compared to that observed with toxic adenomas remains to be elucidated from clinical and biologic points of view.

Although numerous investigations have been carried out on thyroid carcinoma and Graves' disease [14, 33-36], the clinical importance of this association still gives rise to some controversy. In the Cooperative Thyrotoxicosis Follow-up Study by Dobyns et al. [2], only 86 cases of thyroid carcinoma were found in 34,684 hyperthyroid patients, the overall prevalence being $0.2 \%$. In this multicentric study the prevalence of thyroid cancer in patients with Graves' disease was comparable to that in patients with toxic adenoma $(0.4 \%$ and $0.3 \%$, respectively). In contrast to these results, a 2.5 -fold greater frequency of thyroid carcinoma was recently reported in Graves' disease patients in respect to patients with toxic adenoma [1]. Indeed finding a palpable cold nodule in the context of a diffuse hyperfunctioning goiter increases the risk of malignancy $22.2 \%$ to $45.8 \%$ [1,5], compared to that in patients without a recognizable thyroid nodule (2.9\%) [5]. It has been also 
reported that thyroid cancer usually displays a more aggressive behavior in patients with Graves' disease [37]. The reason for this increased aggressiveness is not clear, although it has been suggested that thyroid-stimulating antibodies (TSAb) likely represent a continuous proliferation stimulus [38]. In our population of 38 patients with Graves' disease, all submitted to total thyroidectomy, only one had a palpable "cold" nodule diagnosed as malignant at final histology. The small number of patients presenting with such association did not allow us to draw any significant conclusions concerning the aggressiveness of thyroid carcinoma-hence the need for a more aggressive surgical treatment. However, it should be pointed out that no signs of metastases or extrathyroidal invasion were observed in the two patients presenting with this association. Both are still alive with no evidence of malignancy 15 months and 19 years, respectively, after surgery.

The eventual occurrence of thyroid cancer in association with hyperfunctioning thyroid diseases should always be kept in mind when deciding the most appropriate therapeutic option. Whereas surgery is considered the treatment of choice for multinodular toxic goiter, simple toxic adenomas are preferentially treated by ${ }^{131}$ I radioablation. The possibility of the coexistence of thyroid carcinomas, although usually of the occult type, suggests greater caution. For example, in the case of single toxic nodules a sonographic examination of the thyroid gland may help to identify coexistent subcentrimetric nodules that could harbor occult carcinomas. Eventually, sonography-guided FNA biopsy may be performed on such lesions. The decision between ${ }^{131}$ I radioablation and surgery for treating hyperthyroid patients still represents a clinical dilemma that must be prospectically evaluated in a large cohort of hyperthyroid patients.

\section{Conclusions}

Thyroid cancer should no longer be considered a rare finding in hyperthyroid patients. A potential risk of malignancy exists not only in patients with detectable cold nodules in the context of diffuse toxic goiters but, as our results suggest, also in patients with single toxic adenomas.

\section{Résumé}

Nous avons réalisé une étude rétrospective pour évaluer la prévalence des tumeurs thyroïdiennes malignes chez 202 patients ayant eu une chirurgie pour hyperthyroïdie. Un cancer de la thyroïde a été diagnostiqué chez 12 patients (5.9\%), l'histologie finale détectant 9 cancers papillaires, un cancer folliculaire et 2 cas de cancer de cellules de Hürthle. L'association cancer/hyperthyroïdie a été plus fréquente chez le patient ayant un adénome toxique solitaire que chez ceux ayant un goitre toxique diffus ou multinodulaire. Dans 5 cas, la tumeur maligne a été détectée dans le contexte d'une lésion d'hyperthyroïdie (3 adénomes toxiques et 2 goitres diffus). Chez 8 patients, le diamètre maximal de la lésion maligne a été inférieur à $1 \mathrm{~cm}$ bien que, dans 5 de ces cas, des signes de mauvais pronostic tels l'invasion capsulaire minime ou la multifocalité ont été retrouvée. Tous les patients ayant un cancer de la thyroïde sont actuellement en vie et apparemment sans maladie résiduelle. Nous concluons que les patients ayant une hyperthyroïdie, et en particulier, ceux qui ont un adénome toxique solitaire, doivent être évalués pour éliminer un éventuel cancer associé afin de programmer les options thérapeutiques les plus adaptées.

\section{Resumen}

Se realizó un estudio retrospectivo con el propósito de definir la prevalencia de tumores tiroideos malignos en 202 pacientes sometidos a cirugía por hipertiroidismo. Se diagnosticó cáncer tiroideo en 12 casos $(5.9 \%)$, con un diagnóstico histológico final de 9 carcinomas papilares, 1 carcinoma folicular y 2 carcinomas de células de Hürthle. La concurrencia del hipertiroidismo y el cáncer tiroideo fue más frecuente en pacientes con adenomas tóxicos únicos que en aquellos con bocios tóxicos difusos o multinodulares. En 5 casos se detectó la neoplasia en el contexto de la lesión hipertiroidea ( 3 adenomas tóxicos y 2 bocios difusos). En 8 pacientes la lesión maligna demostró tener un diámetro menor de $1 \mathrm{~cm}$, aunque en 5 de ellos se encontraron hallazgos histológicos desfavorables tales como mínima invasión capsular o multifocalidad. Todos los pacientes en quienes se detectó cáncer tiroideo están vivos en la actualidad y, aparentemente, libres de enfermedad residual. La conclusión es que los pacientes hipertiroideos, en particular aquellos con adenomas tóxicos únicos, deben ser cuidadosamente evaluados a fín de excluir la presencia de una neoplasia maligna asociada y determinar las opciones terapéuticas más apropiadas.

\section{Acknowledgments}

This work has been supported by research grants from Ministero Università e Ricerca Scientifica e Tecnologica (MURST, ex 60\%), Associazione Italiana Ricerca sul Cancro (AIRC), and Consiglio Nazionale delle Ricerche (CNR).

\section{References}

1. Blondeau, B., Legros, A., Renè, L.: Les cancers thyrö̈diens masqès par une hyperthyroïdie. J. Chir. (Paris) 111:271, 1976

2. Dobyns, B.M., Sheline, G.E., Workman, J.B., Tompkins, E.A., McConahey, W.M., Becker, D.V.: Malignant and benign neoplasms of thyroid in patients treated for hyperthyroidism: a report of the Cooperative Thyrotoxicosis Therapy Follow-up Study. J. Clin. Endocrinol. Metab. 38:976, 1974

3. Hancock, B.W., Bing, R.F., Dirmikins, S.M., Munro, D.S., Neal, F.E.: Thyroid carcinoma and concurrent hyperthyroidism. Cancer 39:298, 1977

4. Sokal, J.E.: Incidence of malignancy in toxic and nontoxic malignant lesion. J.A.M.A. 154:1321, 1954

5. Wahl, R.A., Goretzky, P. Neybier, H., Nitchke, J., Linder, M., Röher, H-D.: Coexistence of hyperthyroidism and thyroid cancer. World J. Surg. 6:385, 1982

6. Belfiore, A., Garofalo, M.R., Giuffrida, D., Runello, F., Filetti, S., Fiumara, A., Ippolito, O., Vigneri, R.: Increased aggressiveness of thyroid cancer in patients with Graves' disease. J. Clin. Endocrinol. Metabl. 70:830, 1990

7. Pingitore, R.: Rilievi morfologici autoptici su 111 tiroidi clinicamente normali in un'area italiana senza endemia gozzigena. Pathologica 74:545, 1982

8. Robinson, E., Horn, Y., Hochmann, A.: Incidence of cancer in thyroid nodules. Surg. Gynecol. Obstet. 123:1024, 1966

9. Rosai, J.: Manual of Surgical Pathology Gross Room Procedures. Minneapolis, University of Minnesota Press, 1981, pp. 13-21

10. Hedinger, C.H.R., Sobin, L.H.: Histological typing of thyroid tumors. In International Histological Classification of Tumors (vol. 11). Geneva, World Health Organization, 1974, pp. 17-27 
11. Livadas, D., Psarras, A., Koutras, D.A.: Malignant cold thyroid nodules in hyperthyroidism. Br. J. Surg. 63:726, 1976

12. Shapiro, S.J., Friedman, N.B., Perzik, S.L., Catz, B.: Incidence of thyroid carcinoma in Graves' disease. Cancer 26:1261, 1997

13. Hofstädter, F., Ladurner, D., Leitner, G.: Die endemische Struma vor und nach der Kropfprophylaxe. Dtsch. Med. Wochenschr. 105:296, 1980

14. Walthart, B.: Der gestaltwandel der struma maligna mit bezug auf die jodprophylaxe des kropfes. Schweiz. Med. Wochenschr. 93:809, 1963

15. Autelitano, F., Spagnoli, L.G., Santeusanio, G., Villaschi, S., Autelitano, M.: Occult thyroid carcinoma, epidemiologic study on autoptic material. Ann. Ital. Chir. 61:141, 1990

16. Lang, W., Borrusch, H., Bauer, L.: Occult carcinomas of the thyroid. Am. J. Clin. Pathol. 90:72, 1988

17. Yokozawa, T., Miyauchi, A., Kuma, K., Sugawara, M.: Accurate and simple method of diagnosing thyroid nodules by the modified technique of ultrasound-guided fine needle aspiration biopsy. Thyroid 5:141, 1995

18. Woolner, L.B., Lemmon, M.L., Beahrs, O.H., Black, B.M., Keating, F.R., Jr.: Occult papillary carcinoma of the thyroid: a study of 140 cases observed in a 30-year period. J. Clin. Endocrinol. Metab. 20:89, 1960

19. DeGroot, L.J., Kaplan, E.L., Mecomick, M., Straus, F.H.: Natural history, treatment, and course of papillary thyroid carcinoma. J. Clin. Endocrinol. Metab. 71:414, 1990

20. Danese, D., Sciacchitano, S., Farsetti, A., Andreoli M., Pontecorvi, A.: Diagnostic accuracy of conventional versus sonography-guided fine needle aspiration biopsy of thyroid nodules. Thyroid 8:15, 1998

21. Giuffrida, D., Gharib, H.: Controversies in the management of cold, hot, and occult thyroid nodules. Am. J. Med. 99:642, 1995

22. Hamburger, J.I.: Solitary autonomously functioning thyroid lesions. Am. J. Med. 58:740, 1975

23. Becker, F.O., Economou, P.G., Schwartz, T.B.: The occurrence of carcinoma in "hot" thyroid nodules: report of two cases. Ann. Intern. Med. 58:877, 1963

24. Hoving, J., Piers, D.A., Vermey, A., Oosterhuis, J.W.: Carcinoma in hyperfunctioning thyroid nodule in recurrent hyperthyroidism. Eur. J. Nucl. Med. 6:131, 1981

25. Khan, O., Ell, P.J., Maclennan, K.A., Kurtz, A., Williams, E.S.:

\section{Invited Commentary}

\author{
Malcolm H. Wheeler, M.D. \\ Department of Endocrine Surgery, University Hospital of Wales, \\ Cardiff, U.K.
}

Although the famous Boston physician Howard Means had stated in 1937, "One might almost say that thyrotoxicosis was insurance against cancer of the thyroid" [1], it has since been repeatedly shown that malignancy of the thyroid and thyrotoxicosis may coexist. The excellent article by Zanella and coworkers examines this relation more closely in a range of thyrotoxic disorders. They note an overall cancer prevalence of $5.9 \%$, not dissimilar to previously reported data [2, 3].

Several questions are worthy of consideration.

1. Is there a true association between thyroid cancer and thyrotoxicosis? In the present report most of the tumors were papillary, and autopsy data certainly indicate that this is by no means a rare tumor, most lesions being minimal [4, 5]. A thyroid nodule, particularly when solitary or dominant, raises the possibility of malignancy. It is probable that a cold nodule in a toxic gland is just
Thyroid carcinoma in an autonomously hyperfunctioning thyroid nodule. Postgrad. Med. J. 57:172, 1981

26. Sobel, R.J., Liel, Y., Goldstein, J.: Papillary carcinoma and the solitary autonomously functioning nodule of the thyroid. Isr. J. Med. Sci. $21: 878,1985$

27. Nagai, G.R., Pitts, W.C., Basso, L., Cisco, J.A., McDougall, I.R.: Scintigraphic hot nodules and thyroid carcinoma. Clin. Nucl. Med. 12:123, 1987

28. Clark, O.H.: TSH suppression in the management of thyroid nodules and thyroid cancer. World J. Surg. 5:39, 1981

29. Fukata, S., Tamai, H., Matsubayashi, S., Nagai, K., Hirota, Y., Matsuzuka, F., Katayama, S., Kuma, K., Nagataki, S.: Thyroid carcinoma and hot nodule. Eur. J. Nucl. Med. 13:313, 1987

30. Ghose, M.K., Genuth, S.M., Abellera, R.M., Friedman, S., Lidsky, I.: Functioning primary thyroid carcinoma and metastases producing hyperthyroidism. J. Clin. Endocrinol. Metab. 33:639, 1971

31. Russo, D., Tumino, S., Artuti, F., Vigneri, R., Pontecorvi, A., Filetti, S., Belfiore, A.: Detection of an activating mutation of the thyrotropin receptor in a case of an autonomously hyperfunctioning thyroid insular carcinoma. J. Clin. Endocrinol. Metab. 82:735, 1997

32. Miller, J.M.: Hyperthyroidism from the thyroid follicle with autonomous function. J. Clin. Endocrinol. Metab. 7:177, 1978

33. Farbota, L.M., Calandra, D.B., Lawrence, A.M., Paloyan, R.: Thyroid carcinoma in Graves' disease. Surgery 98:1148, 1985

34. Behar, R., Arganini, M., Wu, T.C., McCormick, M., Straus, F.H., De Groot, L.J., Kaplan, E.L.: Graves' disease and thyroid cancer. Surgery 100:1121, 1986

35. Ozaki, O., Ito, K., Kobayashi, K., Toshima, K., Iwasaki, H., Yashiro, T.: Thyroid carcinoma in Graves' disease. World J. Surg. 14:437, 1990

36. Friedman, N.B., Perzik, S.L., Catz, B.: Incidence of thyroid carcinoma in Graves' disease. Cancer 26:1261, 1970

37. Pacini, F., Elisei, R., Di Coscio, G.C., Anelli, S., Macchia, E., Concetti, R., Miccoli, P., Arganini, M., Pinchera, A.: Thyroid carcinoma in thyrotoxic patients treated by surgery. J. Endocrinol. Invest. 11:107, 1988

38. Filetti, S., Belfiore, A., Amir, S.M., Daniels, G.H., Ippolito, O., Vigneri, R., Ingbar, S.H.: The role of thyroid-stimulating antibodies of Graves' disease in differentiated thyroid cancer. N. Engl. J. Med. 318:753, 1988

as likely to be malignant as a cold nodule in a euthyroid patient [6]. Nevertheless, the malignancy rate of $19.5 \%$ in toxic adenoma patients in the present series is perhaps rather higher than expected.

2. What are the likely mechanisms? Thyrotropin (TSH) stimulates growth and function of differentiated thyroid carcinomas, and it is noted that follicular tumors are more common in endemic goitrous areas. Although TSH levels are low in thyrotoxicosis, it is possible that earlier stimulation of the thyroid gland by TSH might have initiated or promoted changes favorable to subsequent tumor development before the toxic state supervened and suppressed TSH levels. Oncogene activation is likely to be an important factor and clearly requires further evaluation in these particular circumstances.

Dietary factors are also relevant, high iodine intake being linked to papillary carcinoma. In most reported series of thyroid tumors found in association with thyrotoxicosis the lesions have been papillary.

In the case of Graves' disease there may be a role for thyroid-stimulating antibodies in the stimulation and promotion of malignancy. Filetti and colleagues described three patients with concurrent Graves' disease and metastatic thyroid carcinoma whose clinical progress gave some credence to this suggestion [7]. Novel in vitro studies also showed that thyroid-stimulating anti- 
bodies from these patients could stimulate the cells in a follicular thyroid carcinoma line.

3. Are tumors associated with thyrotoxicosis more aggressive? In the present series 8 of 12 tumors were a minimal papillary type, which should (although not invariably) be associated with a good prognosis. Others, however, have stated that tumors found in association with thyrotoxicosis may be more virulent as judged by the presence of lymph node metastasis, distant metastatic disease, and even transformation to undifferentiated carcinoma $[2,8]$.

4. How can malignancy be diagnosed prior to treatment of thyrotoxicosis? Clearly, clinical awareness is vital, and there must be a readiness to perform fine-needle aspiration cytology even on hyperfunctioning nodules as well as coexisting cold nodules. The role of ultrasound-guided needle biopsy has yet to be clearly defined. Conventional soft tissue radiographs of the neck to evaluate thyroid gland calcification can be of some value. In one series of patients with thyroid cancer in Graves' goiters, typical fine calcification was seen in $60 \%$ of the cases; and in most of these the calcification pattern was considered diagnostic of carcinoma [9].

5. What are the implications for treatment? Total thyroidectomy is considered by many to be the appropriate treatment for most thyroid cancers, but such aggressive surgery is not usually performed for thyrotoxicosis except perhaps in selected patients with gross multinodularity, the young with Graves' disease, and those with severe Graves' ophthalmopathy. However, the present article has demonstrated that most tumors found in association with thyrotoxicosis are of the minimal papillary type. These lesions are certainly adequately treated by less than total thyroidectomy, in most instances a unilateral lobectomy being sufficient. These data suggest that surgery should continue to be the mainstay of the treatment of toxic nodular goiter of both the multinodular and solitary varieties.

\section{References}

1. Means, I.H.: The Thyroid and Its Diseases. Philadelphia, Lippincott, 1937, p. 482

2. Behar, R., Arganini, M., Wu, T.C., McCormick, M., Strauss, F.H., DeGroot, L.J., Kaplan, E.L.: Graves' disease and thyroid cancer. Surgery 100:1121, 1986

3. Shapiro, S.J., Friedman, N.P., Perzik, S.L., Catz, B.: Incidence of thyroid carcinoma in Graves' disease. Cancer 26:1261, 1970

4. Nishiyama, R.H., Ludwig, G.K., Thompson, N.W.: The prevalence of small papillary thyroid carcinomas in 100 conservative necropsies in an American population. In DeGroot Radiation Associated Thyroid Carcinoma. Orlando, FL, Grune \& Stratton, 1977, pp. 123-135

5. Fukunaga, F.H., Yatani, R.: Geographic pathology of occult thyroid carcinomas. Cancer 36:1095, 1975

6. Wahl, R.A., Goretzki, P., Meybier, H., Nitschke, J., Linder, M., Roher, H.D.: Co-existance of hyperthyroidism and thyroid cancer. World J. Surg. 6:385, 1982

7. Filetti, S., Belfiore, A., Amir, S.M., Daniels, G.H., Ippolito, O., Vigneri, R., Ingbar, S.H.: The role of thyroid stimulating antibodies of Graves' disease in differentiated thyroid cancer. N. Engl. J. Med. 318:753, 1988

8. Ozaki, O., Ito, K., Kobayashi, K., Toshima, K., Iwasaki, H., Yashiro, T.: Thyroid carcinoma in Graves' disease. World J. Surg. 14:437, 1990

9. Higashi, R., Ito, K., Ozaki, O., Manabe, Y., Suzuki, A., Kobayshi, K., Mimura, T.: Diagnosis of thyroid carcinoma in Graves' disease by thyroid calcification. Jpn. J. Clin. Radiol. 33:351, 1987 